\title{
Testicular Cancer Survivorship
}

\author{
Chunkit Fung, MD, MS ${ }^{a}$; Paul C. Dinh Jr, MPH ${ }^{b, c}$; Sophie D. Fossa, MD, PhD ; and Lois B. Travis, MD, ScD
}

\begin{abstract}
Testicular cancer (TC) is the most common cancer among men aged 18 to 39 years. It is highly curable, with a 10 -year relative survival approaching $95 \%$ due to effective cisplatin-based chemotherapy. Given the increasing incidence of TC and improved survival, TC survivors (TCS) now account for approximately $4 \%$ of all US male cancer survivors. They have also become a valuable cohort for adultonset cancer survivorship research, given their prolonged survival. Commensurately, long-term treatment-related complications have emerged as important survivorship issues. These late effects include life-threatening conditions, such as second malignant neoplasms and cardiovascular disease. Moreover, TCS can also experience hearing loss, tinnitus, neurotoxicity, nephrotoxicity, pulmonary toxicity, hypogonadism, infertility, anxiety, depression, cognitive impairment, and chronic cancer-related fatigue. Characterization of the number and severity of long-term adverse health outcomes among TCS remains critical to develop risk-stratified, evidence-based follow-up guidelines and to inform the development of preventive measures and interventions. In addition, an improved understanding of the long-term effects of TC treatment on mortality due to noncancer causes and second malignant neoplasms remains paramount. Future research should focus on the continued development of large, well-characterized clinical cohorts of TCS for lifelong followup. These systematic, comprehensive approaches can provide the needed infrastructure for further investigation of long-term latency patterns of various medical and psychosocial morbidities and for more in-depth studies investigating associated etiopathogenetic pathways. Studies examining premature physiologic aging may also serve as new frontiers in TC survivorship research.
\end{abstract}

J Natl Compr Canc Netw 2019;17(12):1557-1568 doi: $10.6004 /$ jnccn.2019.7369

\footnotetext{
aUniversity of Rochester School of Medicine and Dentistry, Rochester, New York; bIndiana University Melvin and Bren Simon Cancer Center, Indianapolis, Indiana; 'Department of Epidemiology, Fairbanks School of Public Health, Indiana University, Indianapolis, Indiana; and 'Norwegian Radium Hospital, Oslo, Norway.
}

Although the incidence of testicular cancer (TC) continues to increase globally, ${ }^{1}$ TC mortality has declined, ${ }^{1}$ attributable in large part to cisplatin-based chemotherapy. ${ }^{2}$ Due to the 10 -year relative survival rate approaching $95 \%,{ }^{3}$ treatment-related complications, including second malignant neoplasms (SMNs), cardiovascular disease (CVD), ototoxicity, neurotoxicity, nephrotoxicity, pulmonary toxicity, hypogonadism, infertility, anxiety, depression, cognitive impairment, and chronic cancer-related fatigue, have emerged as critical survivorship issues in this young cohort of survivors. ${ }^{4}$ Platinum agents bind to and damage DNA, producing partly reactive platinum in the serum and platinum-DNA adducts in human organs, detectable up to 20 years after chemotherapy, ${ }^{5}$ and may contribute in part to several toxicities. This article reviews each of these toxicities, with recommended management detailed in supplemental eTable 1, available with this article at JNCCN.org. ${ }^{6-13}$

\section{Overview of TC Management}

Approximately $70 \%$ of patients with stage I nonseminoma and $80 \%$ to $85 \%$ with stage I seminoma are cured with orchiectomy alone and $97 \%$ to $99 \%$ of those who experience relapse are ultimately cured with chemotherapy; thus, surveillance has emerged as an attractive management strategy for stage I TC. ${ }^{14}$ For stage I nonseminoma, adjuvant chemotherapy with 1 cycle of bleomycin/etoposide/cisplatin (BEPX1) and retroperitoneal lymph node dissection (RPLND) are other options, whereas adjuvant chemotherapy with 1 cycle of carboplatin and adjuvant radiotherapy (RT; $20 \mathrm{~Gy}$ ) to the para-aortic lymph nodes are other options for stage I seminoma. Reductions in both RT fields (to include ipsilateral para-aortic lymphatics vs ipsilateral iliac and para-aortic lymphatics) ${ }^{15}$ and doses (20 vs $\left.30 \mathrm{~Gy}\right)^{16}$ were adopted after randomized trials in stage I seminoma showed that these modifications caused no differences in 2 -year TC relapse rates (3.0\% vs $2.3 \%$, respectively). For stage IIA and IIB seminoma, an RT dose of 30 to $35 \mathrm{~Gy}$ may be administered to the infradiaphragmatic area, which extends from the para-aortic region to the proximal

See JNCCN.org for supplemental online content. 
ipsilateral iliac lymph nodes. For selected patients with stage IIB or IIC seminoma, EPX4 or BEPX3 are other options. ${ }^{14}$ Patients with good-risk metastatic TC according to the International Germ Cell Cancer Collaborative Group (IGCCCG) typically receive BEPX3 or EPX4, whereas those with intermediate- or high-risk disease receive BEPX4 or etoposide/ifosfamide/cisplatin (VIPX4). ${ }^{14}$ Approximately $20 \%$ of patients with TC in the United States require salvage therapy. ${ }^{17}$

\section{Second Malignant Neoplasms}

$\mathrm{RT}$ for TC is associated with significant risks of leukemia ${ }^{18}$ and solid cancers. ${ }^{19-22}$ In an international populationbased study of 18,576 TCS, ${ }^{18}$ abdominal and pelvic RT were associated with a significant 3 -fold risk of leukemia $(\mathrm{n}=22$; median latency, 5 years). In another international population-based investigation of 40,576 10-year TCS, ${ }^{20}$ SMN risks in locations typically within infradiaphragmatic RT fields were significantly higher (relative risk $[R R], 2.7 ; n=212)$ compared with unexposed sites (RR, 1.6), and remained elevated for $>35$ years. Another analytic study ${ }^{22}$ of 5-year TCS (1959-1987; stage I/II and III/IV disease: $95.7 \%$ and $4.3 \%$, respectively) reported a significant 5.9-fold risk of stomach cancer $(\mathrm{n}=87)$, with $>20$-fold risks $\left(P_{\text {trend }}<.001\right)$ associated with gastric radiation doses of $\geq 50$ Gy ( 8 cases vs 6 controls) vs $<10 \mathrm{~Gy}$ (15 cases vs 49 controls). A multicenter hospital-based study by Groot et $\mathrm{al}^{21}$ reported that the hazard ratio (HR) of an infradiaphragmatic SMN increased by $8 \%$ per Gy of radiation dose administered $(P<.001)$ compared with TCS who received no para-aortic RT. Groot et $\mathrm{al}^{21}$ reported that TCS had a lower risk of SMN after para-aortic radiation than after dog-leg radiation in a multivariable Cox analysis; however, this same study ${ }^{21}$ did not show a decline in solid SMN risk in patients treated in 1996 through 2007 compared with those treated in earlier decades, likely attributable to the relatively small number of patients with nonseminoma TC in the former period given high-dose RT, which is no longer used as primary treatment of nonseminoma.

Both cisplatin ${ }^{18}$ and etoposide ${ }^{23}$ are associated with elevated risks of secondary leukemia in TCS. Alkylating agent-induced leukemia develops 5 to 8 years after therapy, usually preceded by myelodysplastic syndromes (MDS) with a karyotype involving long-arm deletions or monosomy of chromosomes 5 and 7. Topoisomerase II inhibitor-induced leukemia has a median onset of 2 to 3 years, usually presents without preceding MDS, and is often characterized by balanced translocations involving the MLL (11q23), RARA (17q21), and RUNX1 (21q22) loci. ${ }^{24}$ A series of $>18,000$ TCS (mean follow-up, 10.2 years) reported a significant dose-response relationship between cumulative cisplatin dose and leukemia risk after adjusting for RT dose $\left(P_{\text {trend }}=.001\right) .{ }^{18}$ A cumulative cisplatin dose of $650 \mathrm{mg}$ was associated with a significant 3.2 -fold risk of leukemia ( $\mathrm{n}=16$ excess leukemias), with larger doses (1,000 mg) associated with significant 6 -fold risks. In a separate study, ${ }^{23}$ the 5 -year cumulative incidence of leukemia after cumulative etoposide doses of $<2,000$ and $\geq 2,000 \mathrm{mg} / \mathrm{m}^{2}$ was $0.5 \%$ and $2.0 \%$, respectively. A Danish nationwide cohort study ${ }^{25}$ of 5,190 men with TC (1984-2007) reported a significant 6.3-fold risk of myeloid leukemia after BEP $(P<.001)$ compared with age-matched population-based controls $(n=6$ myeloid leukemia for the entire cohort).

Although most series ${ }^{20,26-28}$ of second solid cancers focused on TCS before the adoption of cisplatin-based chemotherapy, 3 recent studies ${ }^{21,25,29}$ reported significant associations of SMN risk in TCS given modern cisplatinbased chemotherapy. A US population-based investigation $^{29}$ of $>12,000$ TCS treated with cisplatin-based chemotherapy (1980-2008) reported an overall 1.4-fold significant risk of solid cancer $(n=111)$ compared with surgery-only patients, with significant risks of kidney (standardized incidence ratio [SIR], 3.4; $\mathrm{n}=13$ ), thyroid (SIR, 4.4; $\mathrm{n}=11$ ) and soft tissue cancers (SIR, 7.5; $\mathrm{n}=10$ ). In a subsequent Danish population-based study ${ }^{25}$ of 5,190 TCS (1984-2007; median follow-up, 14.4 years), SMN risk after BEP was 1.7-fold higher (95\% CI, 1.4-2.0) compared with surveillance, with a 20-year cumulative SMN incidence of $7.6 \%$ after BEP and a 1.6-fold significant excess mortality due to SMN. Similarly, a multicenter hospital-based Dutch investigation ${ }^{21}$ (median follow-up, 14.1 years) reported that TCS given cisplatin-based chemotherapy had a significant 2.4-fold risk of second solid cancers $(n=151)$ compared with those not treated with chemotherapy. The same $s^{2}{ }^{21}$ reported significant linear dose-dependent increases in the risk of gastrointestinal cancers by $53 \%$ with each additional $100 \mathrm{mg} / \mathrm{m}^{2}$ of platinum-containing chemotherapy $\left(P_{\text {trend }}<.001\right)$, providing evidence of a potential dose-dependent relationship between platinum-based chemotherapy and solid tumors. The risk of gastrointestinal SMN was increased by 3.6 -fold $(n=21)$ and 5.0 -fold $(n=16)$ after 400 to 499 and $\geq 500 \mathrm{mg} / \mathrm{m}^{2}$ of platinum-containing chemotherapy, respectively.

\section{Cardiovascular Disease}

\section{Incidence}

Compared with the general population or TCS under surveillance, those administered chemotherapy showed significantly increased RR for CVD, ranging from 1.4 to 7.1. ${ }^{26,30-32}$ The incidence of angina, myocardial infarction (MI), or sudden cardiac death was $7 \%$ in a British investigation $^{31}$ of 390 TCS given chemotherapy in 1982 through 1992 (median follow-up, 9.7 years). The age-adjusted RR of 
CVD was significantly increased by 2.6 -fold when compared with TCS who had surgery alone. A Norwegian study $^{30}$ of 9905 -year survivors of TC (median followup, 19 years) reported that TCS treated with RT, chemotherapy, and combined RT/chemotherapy had significantly increased prevalence for antihypertensive medication use compared with age-matched male controls in the general population. Compared with controls, the odds ratio $(\mathrm{OR})$ of diabetes was significantly higher in the $\mathrm{RT}(\mathrm{OR}, 2.3)$ and RT/chemotherapy (OR, 3.9) groups. ${ }^{30}$ Compared with surgery only, age-adjusted Cox regression analyses showed significant risks of atherosclerotic disease after RT (HR, 2.3), chemotherapy (HR, 2.6), and RT/chemotherapy (HR, 4.8) $\left(P_{\text {trend }}=.02\right) .^{30}$ Furthermore, the risk of coronary artery disease was significantly increased 5.7-fold compared with surgery only, and MI risk was significantly increased 3.1-fold compared with agematched male controls. ${ }^{30}$ A multi-institution investigation $^{33}$ of 787 TCS (median age, 37.3 years; median follow-up, 4.2 years) showed no significant differences in Framingham Risk Score, reflecting similar CVD risks between EPX4, BEPX3, and BEPX4 in multivariable analysis, but TCS with lower levels of education and physical activity had significantly higher Framingham Risk Scores.

Three hypotheses have been proposed to elucidate the pathophysiology of CVD among TCS administered cisplatin-based chemotherapy. ${ }^{34,35}$ The direct vascular damage hypothesis postulates that cisplatin-based chemotherapy directly damages the vascular endothelium. ${ }^{34}$ The indirect hypothesis proposes that cisplatinbased chemotherapy causes increased prevalence of CVD risk factors, resulting in CVD. ${ }^{34}$ A multiple-hit hypothesis suggests that both chemotherapy-induced damage to vascular endothelium and chemotherapy-related increases in CVD risk factors may contribute to elevated CVD risks in TCS. ${ }^{35}$ A multi-institutional study of 1,214 TCS after cisplatinbased chemotherapy reported that $26 \%$ and $3.9 \%$ of TCS have obesity, with respective body mass indexes of 30 to 39 and $\geq 40 \mathrm{~kg} / \mathrm{m}^{2}$, which is a significant CVD risk factor. ${ }^{36}$

\section{Mortality}

TCS may have increased CVD mortality due to cancer treatments. ${ }^{37}$ An international population-based investigation (1943-2002) reported a significant 1.6-fold risk of mortality due to circulatory disease (median follow-up, 10 years) among TCS who received chemotherapy after $1975 .{ }^{37}$ Compared with TCS with primary testicular germ cell tumor (GCT), a SEER population-based study ${ }^{38}$ showed that TCS with mediastinal or nonmediastinal extragonadal GCT had 4.5- and 2.8-fold significant risks of CVD mortality, respectively, likely attributable to increased numbers of chemotherapy cycles required for treatment. In contrast, another population-based study ${ }^{39}$ of 15,006 TCS managed initially with chemotherapy or surgery alone without RT (1980-2010) reported that significant CVD mortality after chemotherapy was confined to the first year after TC diagnosis (HR, 4.86); distant disease $(P<.05)$ and older age at diagnosis $(P<.01)$ were independent risk factors.

\section{Raynaud Phenomenon}

Raynaud phenomenon (RP) is primarily a clinical manifestation of bleomycin-associated vascular damage, ${ }^{8,40}$ although cisplatin is another chemotherapeutic agent that may contribute to RP. ${ }^{41}$ Approximately $18.7 \%$ to $39.0 \%$ of TCS develop RP within 4 to 12 months of chemotherapy, respectively, with a quarter of them experiencing symptoms up to 20 years. ${ }^{40,41} \mathrm{~A}$ multi-institutional investigation ${ }^{36}$ of 1,214 TCS reported that $15.6 \%, 8.7 \%$, and $9.1 \%$ experienced grade 1,2 , and $3 \mathrm{RP}$, respectively.

\section{Ototoxicity}

Cisplatin causes hearing loss, predominantly in the high frequency range, and tinnitus by damaging the outer hair cells of the cochlea. ${ }^{42,43}$ Almost 1 in 5 (18\%) North American TCS reported severe to profound hearing loss as defined by the American Speech-LanguageHearing Association criteria in a multi-institutional study $^{42}$ (median follow-up, 4.3 years). Supplemental eFigure 1 shows the severity of American SpeechLanguage-Hearing Association-defined hearing loss according to cumulative cisplatin dose. Increasing cumulative cisplatin dose was directly associated with hearing loss at $4,6,8,10$, and $12 \mathrm{kHz}$ ( $P_{\text {trend }}$ for each $<.05$ ), with each $100 \mathrm{mg} / \mathrm{m}^{2}$ increase in cumulative cisplatin dose resulting in a 3.2- $\mathrm{dB}$ impairment in ageadjusted overall hearing threshold $(4-12 \mathrm{kHz} ; P<.001) .^{42}$ Tinnitus $(40 \%$ of TCS) was correlated with reduced hearing at each frequency $(P<.001) .{ }^{42}$ Similarly, Bokemeyer et $\mathrm{al}^{43}$ showed that $20 \%$ of TCS self-reported symptomatic ototoxicity after cisplatin-based chemotherapy, including tinnitus (59\%), hearing loss (18\%), or both (23\%). Half of TCS who received $>400 \mathrm{mg} / \mathrm{m}^{2}$ of cumulative cisplatin dose self-reported tinnitus and hearing loss compared with one-fifth of those given $\leq 400$ $\mathrm{mg} / \mathrm{m}^{2}{ }^{43}$ A Norwegian study ${ }^{44}(\mathrm{n}=292$ cisplatin-treated TCS during 1980-1994) reported that increasing quartiles of residual serum platinum levels were directly associated with tinnitus $(P<.001)$ and hearing impairment $(P=.04)$. Other independent risk factors for ototoxicity included older age, a history of noise exposure, hypertension, impaired baseline hearing, and decreased baseline renal function. ${ }^{42,43}$

Several prior investigations have identified significant associations of various single nucleotide polymorphisms (SNPs) with platinum-related ototoxicity, including megalin (rs2075252), COMT (rs9332377), TPMT (rs12201199), and ACYP2 (rs1872328), as reviewed by 
Wheeler et al. ${ }^{45}$ Recently, WFS1 (rs62283056) ${ }^{45}$ was found to be associated with cisplatin-induced hearing loss in TCS. A variant near OTOS has been associated with cisplatin-induced tinnitus (rs7606353). ${ }^{46}$

\section{Neurotoxicity}

Approximately $20 \%$ to $40 \%$ of TCS report peripheral neuropathy after cisplatin-based chemotherapy, ${ }^{41,47}$ with incidence directly related to cumulative cisplatin dose ${ }^{41,48}$ and possibly residual serum platinum levels. ${ }^{44} \mathrm{~A}$ population-based investigation ${ }^{41}$ of Norwegian TCS (median time after TC treatment, 11 years) reported that $46 \%, 28 \%$, and $10 \%$ of TCS experienced paresthesia after $\geq 5$ cycles of cisplatin-based chemotherapy, 1 to 4 cycles of chemotherapy, and orchiectomy alone, respectively. Compared with TCS who had orchiectomy alone, those who received 1 to 4 cycles and $\geq 5$ cycles of cisplatinbased chemotherapy had significant 2.0- and 3.9-fold risks of paresthesias of the hands, respectively, and significant 2.2- and 3.1-fold risks of paresthesias of the feet, respectively. ${ }^{41}$ RPLND was not an independent risk factor for peripheral neuropathy, but TCS who underwent RT had significant 1.5-fold risk for symptomatic paresthesias of the feet. ${ }^{41}$ Similarly, a population-based study ${ }^{48}$ of Canadian TCS found a significant dose-response effect of chemotherapy on health system visits for neurotoxicity, as measured from 2 years before to 2 years after orchiectomy. Among TCS given 4, 3, and 1 to 2 cycles of chemotherapy, the proportion of patients with healthcare visits for neurotoxicity before and after treatment were as follows: $17 \%$ before vs $37 \%$ after; $17 \%$ before vs $28 \%$ after; and $<13 \%$ before vs $20 \%$ after, respectively $(P=.013){ }^{48}$

Prior studies reported that certain germline SNPs of glutathione $S$-transferase (GST) $P 1^{49}$ and $R P R D 1 B^{50}$ are associated with cisplatin-induced peripheral neuropathy in TCS. The GSTP1-GG genotype conferred a significantly lower risk of paresthesia in the fingers $(\mathrm{OR}, 0.46)$ and toes (OR, 0.42) than the GSTP1-AA and GSTP1-AG genotypes. A genome-wide analysis among TCS reported that lower expression levels of $R P R D 1 B$ were significantly associated with cisplatin-induced peripheral neuropathy. ${ }^{50}$ Expression or knockdown defects of $R P R D 1 B$ disrupt DNA repair mechanisms critical for repairing cisplatin-induced damage. ${ }^{51}$

\section{Nephrotoxicity}

Cisplatin causes primarily proximal and distal renal tubular dysfunction, leading to acute and chronic nephrotoxicity. ${ }^{52}$ Two investigations ${ }^{53,54}$ reported a persistently decreased glomerular filtration rate (GFR) in TCS for years after the end of treatment compared with baseline renal function. More than 10 years after RT $(n=18$ TCS) or cisplatin-based chemotherapy $(n=53$ TCS), a Norwegian study ${ }^{53}$ reported that GFRs decreased by $8 \%$ and $14 \%$, respectively. Both older age at treatment and higher cumulative cisplatin doses were associated with long-term impairment of renal function. ${ }^{53} \mathrm{~A}$ Danish investigation $^{54}$ of 1,206 TC patients treated with BEP reported that GFRs in TCS with normal GFRs before treatment decreased by $11.3 \%, 15.4 \%$, and $25.9 \%$ after 3 , 4 , and $\geq 5$ cycles of BEP, but showed a significant, though incomplete rebound at 1-, 3-, and 5-year follow-up. The GFRs at 5-year follow-up for the 3 chemotherapy groups were approximately $94 \%, 89 \%$, and $78 \%$ of the baseline GFRs, respectively. Treatment-related nephrotoxicity among long-term TCS may contribute in part to increases in incident CVD, including hypertension and MI. ${ }^{30,31}$ Renal function before and after cisplatin-based chemotherapy is an important determinant of long-term exposure to circulating serum platinum, which may be associated in part with several long-term effects of TC treatment. ${ }^{55}$

\section{Pulmonary Toxicity}

Recent series ${ }^{56,57}$ reported no bleomycin-related deaths, likely attributable to bleomycin discontinuation at the earliest sign of pulmonary toxicity. Risk factors for late bleomycin-associated pulmonary toxicity include pulmonary surgery, tobacco use $\geq 20$ pack years, and cumulative cisplatin dose $>850 \mathrm{mg} .{ }^{58}$ A Danish study ${ }^{59}$ of 565 TCS given BEP (median follow-up, 16.1 years; 1984-2007) reported that the cumulative risk of all pulmonary disease was comparable to that of TCS with stage I disease who remained on surveillance, including pulmonary fibrosis $(0.4 \%$ vs $0.2 \%)$, pulmonary embolism $(0 \%$ vs $0.3 \%)$, pneumonia (2.6\% vs $3.3 \%)$, obstructive disease $(3.3 \%$ vs $2.8 \%)$, and pneumothorax $(0.3 \%$ vs $0.4 \%) .{ }^{59}$ Factors that negatively influenced pulmonary function test results included pulmonary surgery, pulmonary embolism, IGCCCG poor-risk TC, and smoking. ${ }^{59}$

A Dutch study ${ }^{60}$ suggests that the HFE gene, which is involved in iron metabolism and homeostasis, may be involved in bleomycin-induced pulmonary toxicity. Among 369 TCS given bleomycin and cisplatin (1978-2006), patients who were heterozygous and homozygous for the $H 63 D$ variant of $H F E$ had a higher frequency of bleomycininduced toxicity ( $21 \%$ and $50 \%$, respectively) compared with those with wild-type $H F E(11 \%)(P=.012) .{ }^{60}$ A prior Dutch investigation ${ }^{61}$ found no significant association of bleomycin-induced pneumonitis or changes in pulmonary function tests with the genetic polymorphism in $B L M H(1450 \mathrm{~A}>\mathrm{G})$ that encodes bleomycin hydrolase, which inactivates bleomycin. ${ }^{62}$

\section{Hypogonadism}

Hypogonadism is directly associated with increased risks of metabolic syndrome, CVD risk factors, and CVD ${ }^{63-66}$ and may also contribute to depression, loss of energy, fertility problems, decreased sexual function, osteoporosis, and muscle weakness. ${ }^{67-73}$ 


\section{Table 1. Self-Reported AHOs}

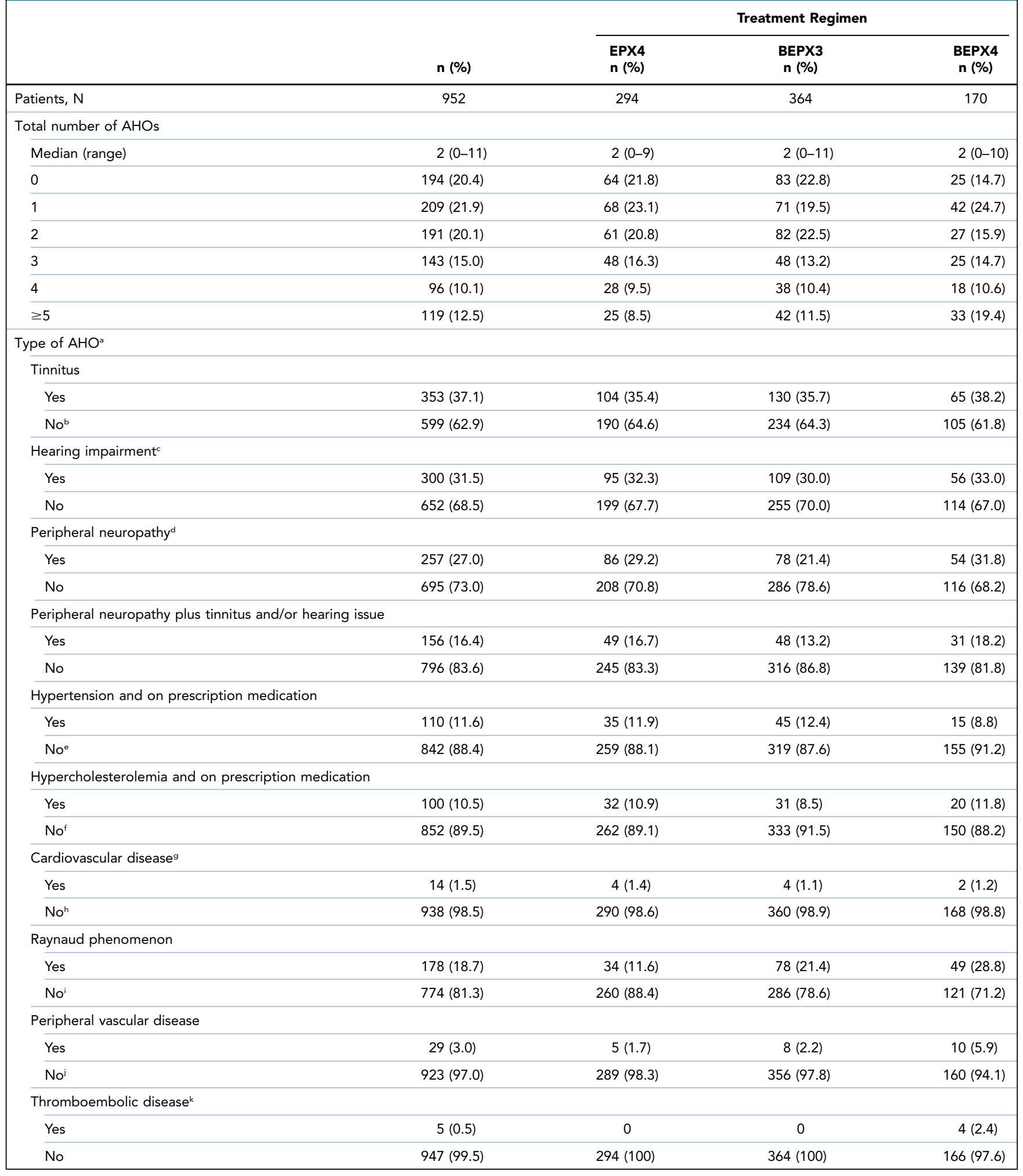




\section{Table 1. Self-Reported AHOs (cont.)}

Treatment Regimen

n (\%)

EPX4 BEPX3

n (\%)

BEPX4

n (\%)

n (\%)

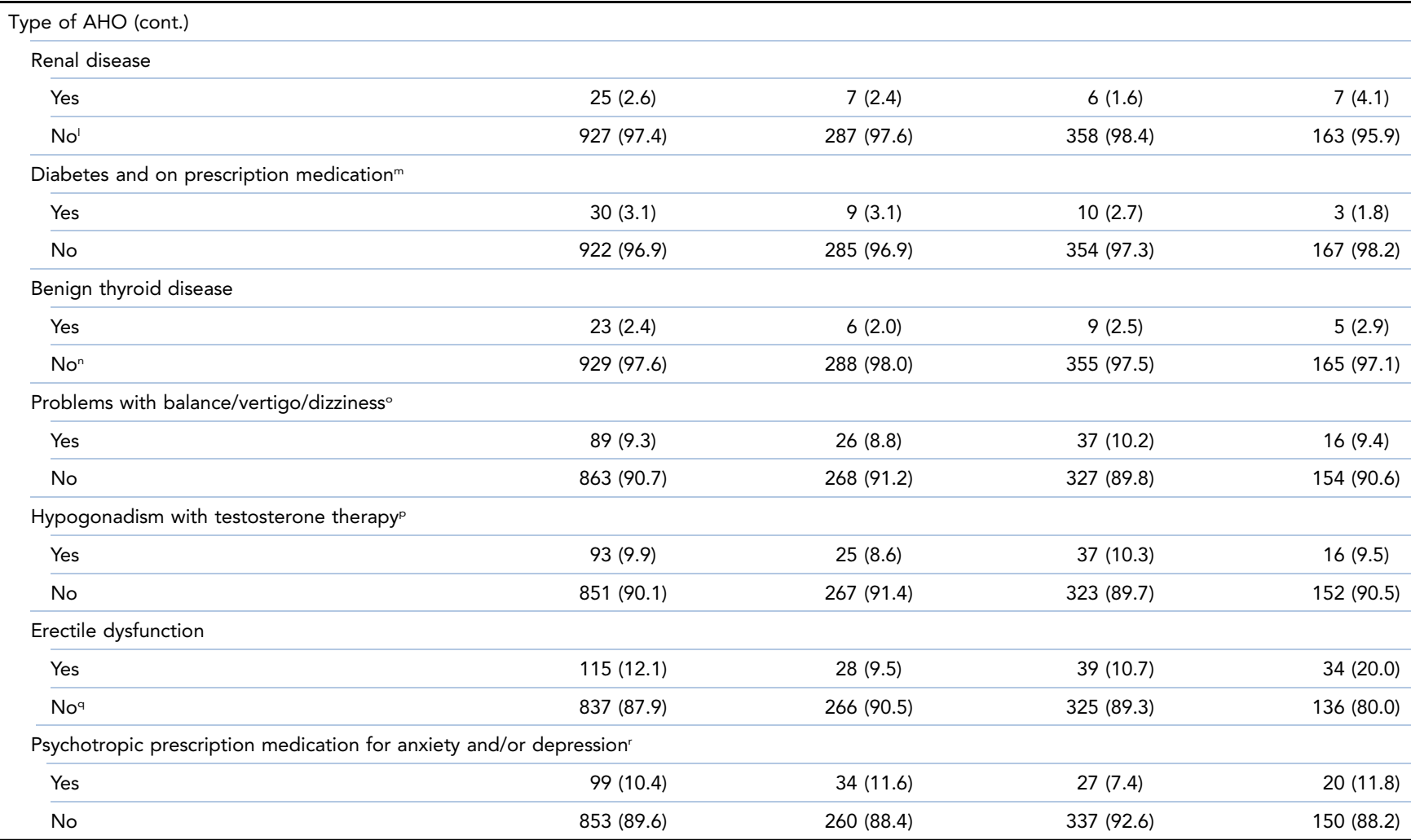

Abbreviations: AHO, adverse health outcome; BEP, bleomycin/etoposide/cisplatin; CAD, coronary artery disease; DVT, deep vein thrombosis; EP, etoposide/ cisplatin; SCIN, Scale for Chemotherapy-Induced Long-Term Neurotoxicity.

a $P$ values were derived from the chi-square test comparing the proportions of $\mathrm{AHO}$ s reported by testicular cancer survivors in the EPX4 and BEPX 3 treatment groups.

$P$ values were $>.05$ for all AHOs except Raynaud phenomenon $(P<.01)$ and peripheral neuropathy $(P=.02)$

bOutcome was not stated for 3 participants.

cAmong all 952 participants, $270(28.4 \%)$ reported problems hearing words, sounds, or language in crowds, $13(1.4 \%)$ required a hearing aid, and $2(0.2 \%)$ had complete deafness (questions derived from the hearing handicap inventory by Ventry and Weinstein $\left.{ }^{111}\right) ; 109$ (11.4\%) had "quite a bit" or "very much" difficulty hearing, and 75 (7.9\%) had "quite a bit" or "very much" reduced hearing (EORTC QLQ-CIPN20 questionnaire and SCIN). ${ }^{112,113}$ Outcome was not stated for 48 participants.

'Among all 952 participants, the number of patients reporting "quite a bit" or "very much" to the following questions are as follows: $123(12.9 \%)$ tingling fingers or hands, $167(17.5 \%)$ tingling toes or feet, $121(12.7 \%)$ numbness in fingers or hands, $161(16.9 \%)$ numbness in toes or feet, 34 (3.6\%) shooting/burning pain in fingers or hands, 70 (7.4\%) shooting/burning pain in toes or feet (EORTC QLQ-CIPN20 questionnaire) ${ }^{112} ; 134$ (14.1\%) pain and tingling in toes or feet, and $86(9.0 \%)$ pain and tingling in hands or fingers (SCIN). ${ }^{113}$ Outcome was not stated for 16 participants.

eOutcome was not stated for 11 participants.

fOutcome was not stated for 3 participants.

Includes $C A D$, heart failure, and cerebrovascular disease (categories not mutually exclusive and each category was counted as one AHO). Among all participants, 7 (0.7\%) reported CAD ( 3 occurrences of CAD, 5 occurrences of angioplasty or stent, and 5 occurrences of heart attack or myocardial infarction); 1 reported heart failure; and 10 $(1.0 \%)$ reported cerebrovascular disease (6 occurrences of transient ischemic attacks, 4 occurrences of stroke, and 1 occurrence of carotid artery surgery).

hOutcome was not stated for 21 participants.

Outcome was not stated for 12 participants.

jOutcome was not stated for 19 participants.

${ }^{k}$ DVT and pulmonary embolism developed simultaneously in 3 participants and was counted as one thromboembolic event for each. The remaining 2 participants reported DVT only. Outcome was not stated for 19 participants.

'Outcome was not stated for 26 participants.

mAmong all participants, $13(1.4 \%)$ and $22(2.3 \%)$ reported use of insulin and oral antiglycemic agents, respectively (categories not mutually exclusive). Outcome was not stated for 15 participants.

nOutcome was not stated for 19 participants.

-Of the 89 patients, 47 reported persistent dizziness or vertigo and 63 reported symptoms of dizziness when standing up (categories not mutually exclusive). Outcome was not stated for 40 participants.

PEight participants who underwent bilateral orchiectomy were excluded from this category.

qOutcome was not stated for 7 participants.

rParticipants could report $>1$ psychotropic medication. Psychotropic medications used by the 99 participants include aripiprazole $(n=2)$, alprazolam $(n=5)$, amphetamine-dextroamphetamine $(n=9)$, bupropion $(n=10)$, buspirone $(n=1)$, citalopram $(n=6)$, clonazepam $(n=8)$, desvenlafaxine $(n=1)$, diazepam $(n=1)$, duloxetine $(n=7)$, escitalopram $(n=16)$, fluvoxamine $(n=1)$, fluoxetine $(n=4)$, hydroxyzine $(n=1)$, lisdexamfetamine $(n=4)$, lorazepam $(n=6)$, methylphenidate $(n=5)$, nortriptyline $(n=2)$, olanzapine $(n=2)$, paroxetine $(n=7)$, trazodone $(n=5)$, sertraline $(n=11)$, and venlafaxine $(n=7)$.

Modified from Fung C, Sesso HD, Williams AM, et al. Multi-institutional assessment of adverse health outcomes among North American testicular cancer survivors after modern cisplatin-based chemotherapy. J Clin Oncol 2017;35:1216-1217, with permission. 
A multi-institutional investigation ${ }^{63}$ reported that approximately $38.5 \%$ of North American TCS (median age, 38 years) had hypogonadism, defined by testosterone levels $\leq 300 \mathrm{ng} / \mathrm{dL}$. Predominant causes of hypogonadism in long-term TCS include orchiectomy, testicular dysgenesis syndrome, RT, and chemotherapy. ${ }^{74}$ When compared with orchiectomy alone, TCS administered standard cisplatin-based chemotherapy and infradiaphragmatic RT had significant 1.8- and 1.6-fold risks of hypogonadism, respectively, as defined by total testosterone levels less than the lower limit of the reference range or use of testosterone replacement therapy ${ }^{75}$ The intensity of TC treatment is directly associated with hypogonadism severity. ${ }^{74-79}$ An investigation of 244 long-term TCS reported that cumulative cisplatin doses of $>400 \mathrm{mg} / \mathrm{m}^{2}$ were associated with significant impairment of Leydig cell function compared with TCS who received no chemotherapy, whereas total cisplatin doses of $\leq 400 \mathrm{mg} / \mathrm{m}^{2}$ showed no significant association. ${ }^{80}$ Increased serum platinum levels had a significant association with hypogonadism $^{55}$ and high luteinizing hormone quartiles. ${ }^{44}$

\section{Infertility}

Orchiectomy, postorchiectomy chemotherapy or RT, and testicular dysgenesis syndrome ${ }^{81}$ have been hypothesized as the predominant etiologies for azoospermia and oligospermia. Overall conception and paternity rates range from $49 \%$ to $88 \%$ among long-term TCS who intended to conceive a child after treatment, as reported in several studies (median follow-up, 7-12 years). ${ }^{79,82-84}$ Approximately half of the patients with newly diagnosed TC have low sperm counts $(<20$ million/mL), decreased motility indices $(<40 \%)$, and large percentages of abnormal sperm cells before receipt of any RT or chemotherapy. ${ }^{85}$ A systematic review ${ }^{86}$ reported that $6 \%$ to $24 \%$ of TCS are azoospermic and 50\% oligozoospermic at TC diagnosis. Because spermatogonia are highly sensitive to $\mathrm{RT},{ }^{87}$ scattered irradiation of the remaining testicle during abdominal RT can adversely affect short-term reproductive function of TCS. ${ }^{88}$ Sperm concentrations nadir approximately 6 months after RT, but most patients $(>90 \%)$ recover sperm counts by 24 months after RT. ${ }^{89}$ A Norwegian TCS study ${ }^{88}$ (median follow-up, 11 years) confirmed that RT had no significant long-term negative effects on sperm counts when compared with a surgery-only cohort.

Cisplatin-based chemotherapy is also associated with risk of infertility. ${ }^{68,84,88}$ After 2, 3, and 4 cycles of cisplatin-based chemotherapy, $100 \%, 83 \%$, and $76 \%$ of Norwegian TCS (median follow-up, 12 years) self-reported posttreatment paternity success, respectively $(P=.022){ }^{84}$ Another study demonstrated that the 15-year actuarial posttreatment paternity rate among TCS treated with a cumulative cisplatin dose $>850 \mathrm{mg}(48 \%)$ was significantly lower compared with the surveillance group and the group that received a cumulative cisplatin dose $\leq 850 \mathrm{mg}$ ( $92 \%$ and $60 \%$, respectively; $P<.001) .{ }^{68}$ Sperm counts and serum level of inhibin $B$ were significantly lower, whereas the serum follicle-stimulating hormone level was significantly higher in TCS who received a cumulative cisplatin dose $>850 \mathrm{mg}$ compared with those who received surgery only or $\leq 850 \mathrm{mg}$ of cumulative cisplatin. ${ }^{88}$ RPLND may cause injury to the retroperitoneal postganglionic sympathetic nerve, causing infertility unless cryopreserved sperm are banked presurgery. Rates of retrograde ejaculation after primary and postchemotherapy nerve-sparing RPLND were $1 \%$ to $9 \%{ }^{90,91}$ and $21 \%$ to $29 \%,,^{91,92}$ respectively.

\section{Anxiety and Depression}

Compared with age-adjusted men in the general population, a Norwegian investigation ${ }^{93}$ (mean follow-up, 11.3 years) showed a higher prevalence of a Hospital Anxiety and Depression Scale-defined anxiety disorder among TCS (19.2\% vs $13.5 \% ; P<.001)$. Anxiety disorders were significantly associated with young age, peripheral neuropathy, economic difficulties, excess alcohol use, sexual concerns, and prior treatment of mental illness. ${ }^{93}$ Another study (mean duration after diagnosis, 11.6 years) reported a $6.1 \%$ prevalence of clinically significant anxiety among German TCS, which was associated with younger age and shorter time from diagnosis. ${ }^{94}$ A systematic review ${ }^{95}$ reported that clinically significant anxiety was more prevalent among TCS $(\sim 20 \%)$ than the general population $(\sim 12.5 \%)$.

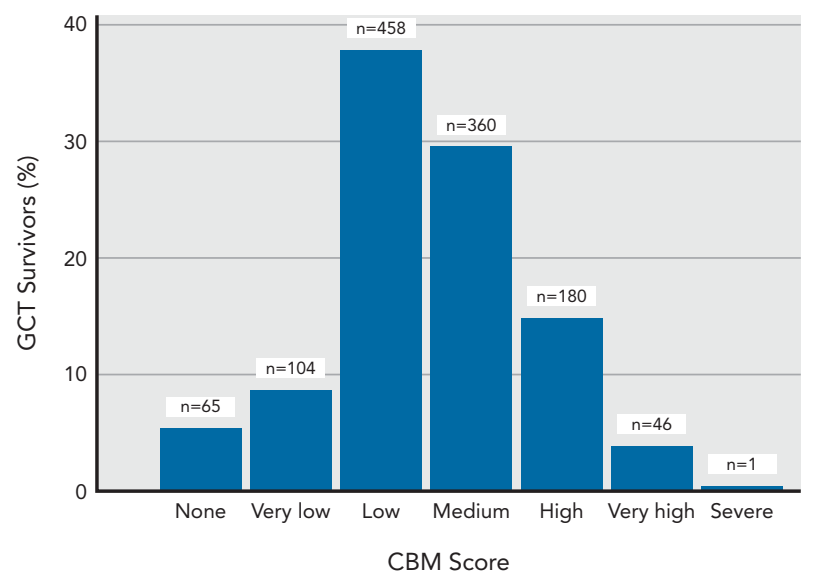

Figure 1. CBM score distribution among 1,214 participants in the Platinum Study. CBM score accounts for the number and severity of the following adverse health outcomes: peripheral sensory neuropathy, autonomic neuropathy, hearing loss/damage, tinnitus, Raynaud phenomenon, pain, kidney disease, hypercholesterolemia, hypertriglyceridemia, hypertension, diabetes, coronary artery disease, transient ischemic attack, stroke, peripheral artery disease, thromboembolic event, obesity, thyroid disease, anxiety/depression, erectile dysfunction, and hypogonadism.

Abbreviations: CBM, cumulative burden of morbidity; $\mathrm{GCT}$, germ cell tumor. From Kerns SL, Fung C, Monahan PO, et al. Cumulative burden of morbidity among testicular cancer survivors after standard cisplatin-based chemotherapy: a multi-institutional study. J Clin Oncol 2018;36:1508, with permission. 


\begin{tabular}{|c|c|c|}
\hline Variable & OR $(95 \% \mathrm{Cl})$ & $P$ Value ${ }^{b}$ \\
\hline Age at evaluation (per $5 \mathrm{y})^{c}$ & $1.18(1.10-1.26)$ & $<.001$ \\
\hline \multicolumn{3}{|l|}{ Time since chemotherapy completion, y } \\
\hline$<2$ & Ref & \\
\hline $2-5$ & $0.91(0.68-1.23)$ & .54 \\
\hline $6-9$ & $0.61(0.42-0.89)$ & .010 \\
\hline$\geq 10$ & $0.55(0.38-0.85)$ & .002 \\
\hline \multicolumn{3}{|l|}{ Race } \\
\hline White & Ref & \\
\hline Black/African American & $1.56(0.49-5.03)$ & .45 \\
\hline Asian & $0.41(0.23-0.72)$ & .002 \\
\hline Other & $1.05(0.63-1.76)$ & .84 \\
\hline \multicolumn{3}{|l|}{ Education } \\
\hline College or postcollege graduate & Ref & \\
\hline Less than college & $1.44(1.11-1.87)$ & .006 \\
\hline \multicolumn{3}{|l|}{ Current employment status } \\
\hline Employed & Ref & \\
\hline Unemployed & $0.90(0.55-1.47)$ & .66 \\
\hline Retired & $1.10(0.36-3.39)$ & .87 \\
\hline Disability leave & $3.53(1.57-7.95)$ & .002 \\
\hline \multicolumn{3}{|l|}{ Smoking status } \\
\hline Never & Ref & \\
\hline Current or former & $1.28(1.02-1.63)$ & .037 \\
\hline
\end{tabular}

(continued)

Abbreviations: BEP, bleomycin/etoposide/cisplatin; CBM, cumulative burden of morbidity; EP, etoposide/cisplatin; MET, metabolic equivalent; OR, odds ratio; RPLND, retroperitoneal lymph node dissection; VIP, etoposide/ ifosfamide/cisplatin

aORs and $P$ values are from an adjusted model that includes all other variables listed in the table as well as enrollment center, with CBM score as the outcome (dependent) variable. The "very high" and "severe" categories were collapsed due to sparse data. Analysis includes 1,013 (83.4\%) testicular cancer survivors with nonmissing data for all variables in the model.

${ }^{b}$ Bold indicates statistical significance at $P<.05$.

'Age at diagnosis was not included in the model given the strong correlation with age at evaluation $(r=0.81)$, which was included.

Prior studies ${ }^{93,94,96-98}$ reported that the prevalence of depression among TCS ranges from $7.9 \%$ to $29.2 \%$, but the extent to which TCS may experience significantly more depressive orders versus the general population is uncertain. Several factors are significantly associated with higher levels of depression, including feeling helpless/ hopeless, ${ }^{97}$ less social support, ${ }^{97}$ a higher number of physical symptoms,${ }^{94}$ and having children. ${ }^{94}$

\section{Other Complications}

Cisplatin-based chemotherapy may have neurotoxic effects, causing cognitive impairment, although underlying mechanisms have not yet been elucidated. Two studies of the same cohort of TCS reported that those

\begin{tabular}{|c|c|c|}
\hline Variable & OR $(95 \% \mathrm{Cl})$ & $P$ Value ${ }^{b}$ \\
\hline \multicolumn{3}{|c|}{ Vigorous physical activity $(\geq 6 \mathrm{METs})^{d}$} \\
\hline No & Ref & \\
\hline Yes & $0.68(0.52-0.89)$ & .004 \\
\hline \multicolumn{3}{|l|}{ RPLNDe } \\
\hline No & Ref & \\
\hline Yes & $0.88(0.69-1.12)$ & .31 \\
\hline \multicolumn{3}{|c|}{ Type of chemotherapyf } \\
\hline BEPX3 & Ref & \\
\hline EPX4 & $1.09(0.75-1.60)$ & .65 \\
\hline BEPX4 & $1.44(1.04-1.98)$ & .028 \\
\hline VIPX4 & $1.96(1.04-3.71)$ & .039 \\
\hline
\end{tabular}

Abbreviations: BEP, bleomycin/etoposide/cisplatin; CBM, cumulative burden of morbidity; EP, etoposide/cisplatin; MET, metabolic equivalent; OR, odds ratio; RPLND, retroperitoneal lymph node dissection; VIP, etoposide/ ifosfamide/cisplatin

aORs and $P$ values are from an adjusted model that includes all other variables listed in the table as well as enrollment center, with CBM score as the outcome (dependent) variable. The "very high" and "severe" categories were collapsed due to sparse data. Analysis includes $1,013(83.4 \%)$ testicular cancer survivors with nonmissing data for all variables in the model.

bBold indicates statistical significance at $P<.05$.

dExercise was assessed in this study using a validated questionnaire that asks participants to report their average time per week (over the past year) spent at each of 9 recreational activities: walking or hiking (including walking to work); jogging (slower than 10-min miles); running (10-min miles or faster); bicycling (including stationary bike); aerobic exercise or dance/ exercise machines; lower intensity exercise/yoga/stretching/toning; tennis, squash or racquetball; lap swimming; and weight lifting/strength training. Each physical activity was assigned a MET value. MET values are a commonly used metric for describing the relative energy expenditure of a specific type of physical activity $(1 \mathrm{MET}=1 \mathrm{kcal} / \mathrm{kg} / \mathrm{h}$, or the energy cost of sitting quietly). The MET values for each activity were then used to calculate MET hours/week for each participant, and these were grouped into categories of vigorous or nonvigorous physical activity following standard definitions.

eRPLND was retained in the multivariable model to control for potential residual confounding, given its correlation with chemotherapy regimen $(P<.001)$; approximately $34 \%, 55 \%, 66 \%$, and $44 \%$ of TCS treated with BEPX3 EPX4, BEPX4, and VIPX4, respectively, had an RPLND.

${ }^{f}$ Disease stage was not significantly associated with CBM score $(P=.48)$, suggesting that increased scores after BEPX4 or VIPX4 were not explained by more advanced tumor status.

Modified from Kerns SL, Fung C, Monahan PO, et al. Cumulative burden of morbidity among testicular cancer survivors after standard cisplatin-based chemotherapy: a multi-institutional study. J Clin Oncol 2018;36:1509, with permission.

who received chemotherapy $(\mathrm{n}=22)$ had altered global and local brain network properties between baseline and follow-up ${ }^{99}$ and widespread brain gray matter reductions with prefrontal reductions on whole-brain MRI, compared with TCS who underwent surveillance $(n=43){ }^{100}$ Despite these findings, the association of cisplatin-based chemotherapy with cognitive impairment in TCS remains unclear. The prevalence of cognitive impairment in patients with newly diagnosed TC prechemotherapy ranges from $46 \%$ to $58 \%$, which is higher than in 
normal populations $(P<.01){ }^{101,102}$ Furthermore, although 3 investigations ${ }^{103-105}$ reported significant risks of cognitive impairment after chemotherapy $(\mathrm{n}=69-1,173$; median follow-up, $1-10$ years), 3 other studies ( $n=70-112$ TCS; median follow-up, 1-3 years) reported no significant differences in performance on cognitive tests between various TC treatment cohorts (ie, surgery only vs chemotherapy).

Chronic cancer-related fatigue (CRF) is defined as a distressing, persistent physical, emotional, and/or cognitive tiredness/exhaustion with a duration of $\geq 6$ months that is related to cancer and/or its treatment, is not proportional to recent activity, and interferes with usual functioning. ${ }^{106}$ The prevalence of chronic CRF among Norwegian TCS was $17.1 \%$ compared with $9.7 \%$ in age-matched men in the general population $(P<.001) .{ }^{107}$ In another study of Norwegian TCS (1980-1994), the prevalence of chronic CRF increased significantly from $15 \%$ at survey I (1998-2002) to $27 \%$ at survey II (2007-2008). ${ }^{108}$ Chronic CRF was significantly associated with peripheral neuropathy, RP, testosterone levels in the lowest quartile, low levels of physical activity, and anxiety/depression. ${ }^{108} \mathrm{~A}$ phase II randomized controlled trial among Canadian TCS ${ }^{109}$ reported that highintensity training significantly improved CRF compared with usual care $(P=.003)$, with its effects persisting at a 3-month follow-up. A meta-analysis of cancer survivors ${ }^{110}$ similarly reported that exercise and psychological interventions were more effective than pharmaceutical options in reducing CRF during and after cancer treatment.

\section{AHOs and Cumulative Morbidity}

Characterization of the number and severity of longterm adverse health outcomes (AHOs) among TCS is critically important for the development of risk-stratified, evidence-based follow-up guidelines. A multi-institutional study ${ }^{40}$ among North American TCS (median age, 37 years) after cisplatin-based chemotherapy showed that $37.6 \%$ of TCS reported $\geq 3$ AHOs with similar prevalence and types after treatment with EPX4 and BEPX3; exceptions were RP (11.6\% vs $21.4 \% ; P<.01)$, peripheral neuropathy (29.2\% vs $21.4 \%$; $P=.02)$, and obesity $(25.5 \%$ vs $33.0 \%$; $P=.04$ ) (Table 1). A follow-up investigation ${ }^{36}$ characterized the cumulative burden of morbidity (CBM) due to AHOs using a score that encompassed both AHO number and severity; approximately $20 \%$ of 1,214 TCS had a CBM score of high (14.8\%) or very high/severe (3.9\%), whereas almost $80 \%$ scored medium (29.7\%) or low/very low (46.3\%) (Figure 1). Higher CBM scores were significantly associated with VIPX4 (OR, 2.0) or BEPX4 (OR, 1.4 vs BEPX3), older attained age (OR, 1.2), current disability leave $(\mathrm{OR}, 3.5)$, lessthan-college education (OR, 1.4), and current or former smoking status (OR, 1.3) (Table 2). This same study ${ }^{36}$ identified 6 clusters of AHOs (chi-square $P<.001$ ): (1) hearing loss/damage, tinnitus (OR, 16.3); (2) hyperlipidemia, hypertension, diabetes (OR, 9.8); (3) neuropathy, pain, RP
(OR, 5.5); (4) cardiovascular and related conditions (OR, 5.0); (5) thyroid disease, erectile dysfunction (OR, 4.2); and (6) depression/anxiety, hypogonadism (OR, 2.8).

\section{Long-Term Survival and Causes of Death}

Understanding the long-term effects of TC treatment on mortality risks due to noncancer causes and SMN is important. A population-based investigation ${ }^{37}$ of 38,907 1-year TCS in North America and Europe (1943-2002) reported that TCS had a significant $6 \%$ excess risk of mortality from noncancer causes compared with the general population; including 1.3- and 1.4-fold mortality from infections and digestive diseases, respectively. TCS given chemotherapy (with or without RT) in 1975 or later when cisplatin-based chemotherapy was introduced had significantly higher mortality from noncancer causes (standardized mortality ratio [SMR], 1.4), including circulatory diseases (SMR, 1.6), infections (SMR, 2.5), and respiratory disease (SMR, 2.5). ${ }^{37}$ Another SEER Program study $^{114}$ (1973-2009) reported that 15-year non-cancerrelated and other-cancer mortality significantly increased with advancing stage and age at diagnosis among TCS using a competing-risks Poisson regression analysis (all $P \leq .001$ ); no data, however, were reported on the effect of treatment.

\section{Conclusions}

TCS account for approximately $4 \%$ of all male cancer survivors ${ }^{115}$ and have become a valuable cohort for research on adult-onset cancer survivorship, given their long-term survival. ${ }^{116}$ Future research should focus on developing longitudinal cohort studies to investigate the cumulative burden and latency trends of various medical and psychosocial morbidities, stratified by treatment type. By gathering comprehensive exposure and outcomes data, this type of investigation would provide information to help identify predictors of AHOs, with the ultimate goal to not only develop preventive and interventional strategies but also enable risk-adapted follow-up. Another critical research goal is to understand genetic variants that predispose TCS to acute and long-term AHOs. This type of elucidation of etiopathogenetic pathways would provide additional foundational support to develop riskbased, targeted prevention and intervention approaches. Finally, increasing evidence suggests that premature physiologic aging develops in survivors of childhood cancer after cytotoxic therapies, with hypothesized mechanisms including increased cellular senescence, reduced telomere length, epigenetic modifications, somatic mutations, and mitochondrial DNA infidelity. ${ }^{117}$ This area of research may also serve as a new frontier for TC survivorship.

Submitted July 20, 2019; accepted for publication October 14, 2019. 
Disclosures: The authors have disclosed that they have no financial interests arrangements, or affiliations with the manufacturers of any products discussed in this article or their competitors.
Correspondence: Lois B. Travis, MD, ScD, Indiana University Melvin and Bren Simon Cancer Center, 535 Barnhill Drive, RT433, Indianapolis, IN 46202. Email: Ibtravis@iu.edu

\section{References}

1. Park JS, Kim J, Elghiaty A, et al. Recent global trends in testicular cancer incidence and mortality. Medicine (Baltimore) 2018;97:e12390.

2. Einhorn LH, Donohue J. Cis-diamminedichloroplatinum, vinblastine, and bleomycin combination chemotherapy in disseminated testicular cancer. Ann Intern Med 1977;87:293-298.

3. Verdecchia A, Francisci S, Brenner $\mathrm{H}$, et al. Recent cancer survival in Europe: a 2000-02 period analysis of EUROCARE-4 data. Lancet Oncol 2007;8:784-796.

4. Fung C, Dinh P Jr, Ardeshir-Rouhani-Fard S, et al. Toxicities associated with cisplatin-based chemotherapy and radiotherapy

in long-term testicular cancer survivors. Adv Urol 2018;2018:8671832.

5. Brouwers EE, Huitema AD, Beijnen JH, et al. Long-term platinum retention after treatment with cisplatin and oxaliplatin. BMC Clin Pharmacol 2008;8:7

6. Wood ME, Vogel V, Ng A, et al. Second malignant neoplasms: assessment and strategies for risk reduction. J Clin Oncol 2012;30:3734-3745.

7. Goff DC Jr, Lloyd-Jones DM, Bennett G, et al. 2013 ACC/AHA guideline on the assessment of cardiovascular risk: a report of the American College of Cardiology/American Heart Association Task Force on Practice Guidelines. Circulation 2014;129(25 Suppl 2):S49-73.

8. Wigley FM, Flavahan NA. Raynaud's phenomenon. N Engl J Med 2016; 375:556-565.

9. Hershman DL, Lacchetti $\mathrm{C}, \mathrm{Dworkin} \mathrm{RH}$, et al. Prevention and management of chemotherapy-induced peripheral neuropathy in survivors of adult cancers: American Society of Clinical Oncology clinical practice guideline. J Clin Oncol 2014;32:1941-1967.

10. Haugnes HS, Bosl GJ, Boer H, et al. Long-term and late effects of germ cell testicular cancer treatment and implications for follow-up. J Clin Oncol 2012;30:3752-3763.

11. Hartmann JT, Kollmannsberger C, Kanz L, et al. Platinum organ toxicity and possible prevention in patients with testicular cancer. Int J Cancer 1999;83:866-869.

12. Loren AW, Mangu PB, Beck LN, et al. Fertility preservation for patients with cancer: American Society of Clinical Oncology clinical practice guideline update. J Clin Oncol 2013;31:2500-2510.

13. Schagen SB, Boogerd W, Muller MJ, et al. Cognitive complaints and cognitive impairment following BEP chemotherapy in patients with testicular cancer. Acta Oncol 2008;47:63-70.

14. Hanna NH, Einhorn LH. Testicular cancer-discoveries and updates. N Engl J Med 2014;371:2005-2016

15. Fosså SD, Horwich A, Russell JM, et al. Optimal planning target volume for stage I testicular seminoma: a Medical Research Council randomized trial. J Clin Oncol 1999;17:1146.

16. Jones WG, Fossa SD, Mead GM, et al. Randomized trial of 30 versus $20 \mathrm{~Gy}$ in the adjuvant treatment of stage I testicular seminoma: a report on Medical Research Council Trial TE18, European Organisation for the Research and Treatment of Cancer Trial 30942 (ISRCTN18525328). J Clin Oncol 2005;23:1200-1208.

17. Adra N, Einhorn LH. Salvage therapy for relapsed testicular cancer. Oncotarget 2017;8:78253-78254.

18. Travis LB, Andersson M, Gospodarowicz M, et al. Treatment-associated eukemia following testicular cancer. J Natl Cancer Inst 2000;92: 1165-1171.

19. Travis LB, Curtis RE, Storm H, et al. Risk of second malignant neoplasms among long-term survivors of testicular cancer. J Natl Cancer Inst 1997;89:1429-1439.

20. Travis LB, Fosså SD, Schonfeld SJ, et al. Second cancers among 40,576 testicular cancer patients: focus on long-term survivors. J Natl Cancer Inst 2005:97:1354-1365.

21. Groot HJ, Lubberts $\mathrm{S}$, de Wit $\mathrm{R}$, et al. Risk of solid cancer after treatment of testicular germ cell cancer in the platinum era. J Clin Oncol 2018;36: 2504-2513.

22. Hauptmann M, Fossa SD, Stovall M, et al. Increased stomach cancer risk following radiotherapy for testicular cancer. Br J Cancer 2015;112: 44-51.
23. Kollmannsberger C, Hartmann JT, Kanz L, et al. Therapy-related malignancies following treatment of germ cell cancer. Int J Cancer 1999;83: 860-863.

24. Fung C, Bhatia S, Allan JM, et al. Second cancers. In: DeVita VT, Rosenberg SA, Lawrence TS, eds. DeVita, Hellman, and Rosenberg's Cancer: Principles \& Practice of Oncology, 11th ed. Philadelphia, PA: Wolters Kluwer; 2017:2155-2173.

25. Kier MG, Hansen MK, Lauritsen J, et al. Second malignant neoplasms and cause of death in patients with germ cell cancer: a Danish nationwide cohort study. JAMA Oncol 2016;2:1624-1627.

26. van den Belt-Dusebout AW, de Wit R, Gietema JA, et al. Treatmentspecific risks of second malignancies and cardiovascular disease in 5-year survivors of testicular cancer. J Clin Oncol 2007;25:4370-4378.

27. Bokemeyer C, Schmoll HJ. Secondary neoplasms following treatment of malignant germ cell tumors. J Clin Oncol 1993;11:1703-1709.

28. Wanderås EH, Fosså SD, Tretli S. Risk of subsequent non-germ cell cancer after treatment of germ cell cancer in 2006 Norwegian male patients. Eur J Cancer 1997;33:253-262.

29. Fung C, Fossa SD, Milano MT, et al. Solid tumors after chemotherapy or surgery for testicular nonseminoma: a population-based study. J Clin Oncol 2013;31:3807-3814

30. Haugnes HS, Wethal $\mathrm{T}$, Aass $\mathrm{N}$, et al. Cardiovascular risk factors and morbidity in long-term survivors of testicular cancer: a 20-year follow-up study. J Clin Oncol 2010;28:4649-4657.

31. Huddart RA, Norman A, Shahidi M, et al. Cardiovascular disease as a long-term complication of treatment for testicular cancer. J Clin Oncol 2003;21:1513-1523.

32. Meinardi MT, Gietema JA, van der Graaf WT, et al. Cardiovascular morbidity in long-term survivors of metastatic testicular cancer. J Clin Oncol 2000;18:1725-1732.

33. Feldman DR, Ardeshir-Rouhani-Fard S, Monahan $\mathrm{P}$, et al. Predicting cardiovascular disease among testicular cancer survivors after modern cisplatin-based chemotherapy: application of the Framingham Risk Score. Clin Genitourin Cancer 2018;16:e761-769.

34. Feldman DR, Schaffer WL, Steingart RM. Late cardiovascular toxicity following chemotherapy for germ cell tumors. J Natl Compr Canc Netw 2012;10:537-544.

35. Jones LW, Haykowsky MJ, Swartz JJ, et al. Early breast cancer therapy and cardiovascular injury. J Am Coll Cardiol 2007;50:1435-1441.

36. Kerns SL, Fung C, Monahan PO, et al. Cumulative burden of morbidity among testicular cancer survivors after standard cisplatin-based chemotherapy: a multi-institutional study. J Clin Oncol 2018;36:1505-1512.

37. Fosså SD, Gilbert E, Dores GM, et al. Noncancer causes of death in survivors of testicular cancer. J Natl Cancer Inst 2007;99:533-544.

38. Alanee SR, Feldman DR, Russo P, Konety B. Long-term mortality in patients with germ cell tumors: effect of primary cancer site on cause of death. Urol Oncol 2014;32:26.e9-15.

39. Fung C, Fossa SD, Milano MT, et al. Cardiovascular disease mortality after chemotherapy or surgery for testicular nonseminoma: a populationbased study. J Clin Oncol 2015;33:3105-3115.

40. Fung $C$, Sesso HD, Williams AM, et al. Multi-institutional assessment of adverse health outcomes among North American testicular cancer survivors after modern cisplatin-based chemotherapy. J Clin Oncol 2017;35:1211-1222.

41. Brydøy M, Oldenburg J, Klepp O, et al. Observational study of prevalence of long-term Raynaud-like phenomena and neurological side effects in testicular cancer survivors. J Natl Cancer Inst 2009;101:1682-1695

42. Frisina RD, Wheeler HE, Fossa SD, et al. Comprehensive audiometric analysis of hearing impairment and tinnitus after cisplatin-based chemotherapy in survivors of adult-onset cancer. J Clin Oncol 2016;34:2712-2720.

43. Bokemeyer C, Berger CC, Hartmann JT, et al. Analysis of risk factors for cisplatin-induced ototoxicity in patients with testicular cancer. $\mathrm{Br} \mathrm{J}$ Cancer 1998:77:1355-1362.

44. Hjelle LV, Bremnes RM, Gundersen PO, et al. Associations between longterm serum platinum and neurotoxicity and ototoxicity, endocrine gonadal function, and cardiovascular disease in testicular cancer survivors. Urol Oncol 2016:34:487.013-487.e20. 
45. Wheeler HE, Gamazon ER, Frisina RD, et al. Variants in WFS1 and other Mendelian deafness genes are associated with cisplatin-associated ototoxicity. Clin Cancer Res 2017;23:3325-3333.

46. El Charif O, Mapes B, Trendowski MR, et al. Clinical and genome-wide analysis of cisplatin-induced tinnitus implicates novel ototoxic mechanisms. Clin Cancer Res 2019;25:4104-4116.

47. Glendenning JL, Barbachano Y, Norman AR, et al. Long-term neurologic and peripheral vascular toxicity after chemotherapy treatment of testicular cancer. Cancer 2010;116:2322-2331.

48. Raphael MJ, Wei X, Karim S, et al. Neurotoxicity among survivors of testicular cancer: a population-based study. Clin Oncol (R Coll Radiol) 2019;31:653-658.

49. Oldenburg J, Kraggerud SM, Brydøy M, et al. Association between longterm neuro-toxicities in testicular cancer survivors and polymorphisms in glutathione-s-transferase-P1 and -M1, a retrospective cross sectional study. J Transl Med 2007;5:70.

50. Dolan ME, El Charif O, Wheeler HE, et al. Clinical and genome-wide analysis of cisplatin-induced peripheral neuropathy in survivors of adultonset cancer. Clin Cancer Res 2017;23:5757-5768.

51. Sawant A, Kothandapani A, Zhitkovich A, et al. Role of mismatch repair proteins in the processing of cisplatin interstrand cross-links. DNA Repair (Amst) 2015;35:126-136.

52. Vickers AE, Rose K, Fisher R, et al. Kidney slices of human and rat to characterize cisplatin-induced injury on cellular pathways and morphology. Toxicol Pathol 2004;32:577-590.

53. Fosså SD, Aass N, Winderen $\mathrm{M}$, et al. Long-term renal function after treatment for malignant germ-cell tumours. Ann Oncol 2002;13:222-228.

54. Lauritsen J, Mortensen MS, Kier MG, et al. Renal impairment and late toxicity in germ-cell cancer survivors. Ann Oncol 2015;26:173-178.

55. Boer $\mathrm{H}$, Proost JH, Nuver J, et al. Long-term exposure to circulating platinum is associated with late effects of treatment in testicular cancer survivors. Ann Oncol 2015;26:2305-2310.

56. de Wit R, Roberts JT, Wilkinson PM, et al. Equivalence of three or four cycles of bleomycin, etoposide, and cisplatin chemotherapy and of a 3or 5-day schedule in good-prognosis germ cell cancer: a randomized study of the European Organization for Research and Treatment of Cancer Genitourinary Tract Cancer Cooperative Group and the Medical Research Council. J Clin Oncol 2001;19:1629-1640.

57. Motzer RJ, Nichols CJ, Margolin KA, et al. Phase III randomized trial of conventional-dose chemotherapy with or without high-dose chemotherapy and autologous hematopoietic stem-cell rescue as first-line treatment for patients with poor-prognosis metastatic germ cell tumors. $\mathrm{J}$ Clin Oncol 2007;25:247-256.

58. Haugnes HS, Aass N, Fosså SD, et al. Pulmonary function in long-term survivors of testicular cancer. J Clin Oncol 2009;27:2779-2786.

59. Lauritsen J, Kier MG, Bandak M, et al. Pulmonary function in patients with germ cell cancer treated with bleomycin, etoposide, and cisplatin. J Clin Oncol 2016;34:1492-1499.

60. van der Schoot GG, Westerink NL, Lubberts S, et al. Variation in the HFE gene is associated with the development of bleomycin-induced pulmonary toxicity in testicular cancer patients. Eur J Cancer 2016;59:134-141.

61. Nuver J, Lutke Holzik MF, van Zweeden M, et al. Genetic variation in the bleomycin hydrolase gene and bleomycin-induced pulmonary toxicity in germ cell cancer patients. Pharmacogenet Genomics 2005;15:399-405.

62. Ferrando AA, Pendás AM, Llano $E$, et al. Gene characterization, promoter analysis, and chromosomal localization of human bleomycin hydrolase. J Biol Chem 1997;272:33298-33304.

63. Abu Zaid M, Dinh PC, Monahan PO, et al. Adverse health outcomes in relationship to hypogonadism after chemotherapy: a multicenter study of testicular cancer survivors. J Natl Compr Canc Netw 2019;17:459-468.

64. Bogefors C, Isaksson S, Bobjer J, et al. Hypogonadism in testicular cancer patients is associated with risk factors of cardiovascular disease and the metabolic syndrome. Andrology 2017;5:711-717.

65. Strumberg D, Brügge S, Korn MW, et al. Evaluation of long-term toxicity in patients after cisplatin-based chemotherapy for non-seminomatous testicular cancer. Ann Oncol 2002;13:229-236.

66. Bokemeyer C, Berger CC, Kuczyk MA, et al. Evaluation of long-term toxicity after chemotherapy for testicular cancer. J Clin Oncol 1996;14:2923-2932.

67. Eberhard J, Ståhl O, Cohn-Cedermark G, et al. Sexual function in men treated for testicular cancer. J Sex Med 2009;6:1979-1989.

68. Brydøy M, Fosså SD, Klepp O, et al. Paternity following treatment for testicular cancer. J Natl Cancer Inst 2005;97:1580-1588.

69. Dahl AA, Bremnes $R$, Dahl O, et al. Is the sexual function compromised in long-term testicular cancer survivors? Eur Urol 2007;52:1438-1447.
70. Hintikka J, Niskanen L, Koivumaa-Honkanen $\mathrm{H}$, et al. Hypogonadism, decreased sexual desire, and long-term depression in middle-aged men J Sex Med 2009;6:2049-2057.

71. Bhasin S, Cunningham GR, Hayes FJ, et al. Testosterone therapy in men with androgen deficiency syndromes: an Endocrine Society clinical practice guideline. J Clin Endocrinol Metab 2010;95:2536-2559.

72. Ondrusova $M$, Ondrus $D$, Dusek $L$, et al. Damage of hormonal function and bone metabolism in long-term survivors of testicular cancer. Neoplasma 2009;56:473-479.

73. Rochira $\mathrm{V}$, Balestrieri A, Madeo B, et al. Osteoporosis and male agerelated hypogonadism: role of sex steroids on bone (patho)physiology. Eur J Endocrinol 2006;154:175-185.

74. Sprauten M, Brydøy M, Haugnes HS, et al. Longitudinal serum testosterone, luteinizing hormone, and follicle-stimulating hormone levels in a population-based sample of long-term testicular cancer survivors. J Clin Oncol 2014;32:571-578.

75. Bandak M, Jørgensen N, Juul A, et al. Testosterone deficiency in testicular cancer survivors-a systematic review and meta-analysis. Andrology 2016;4:382-388.

76. Eberhard J, Ståhl O, Cwikiel M, et al. Risk factors for post-treatment hypogonadism in testicular cancer patients. Eur J Endocrinol 2008;158:561-570.

77. Nord C, Bjøro T, Ellingsen D, et al. Gonadal hormones in long-term survivors 10 years after treatment for unilateral testicular cancer. Eur Urol 2003;44:322-328.

78. Brydøy M, Fosså SD, Dahl O, et al. Gonadal dysfunction and fertility problems in cancer survivors. Acta Oncol 2007;46:480-489.

79. Huddart RA, Norman A, Moynihan C, et al. Fertility, gonadal and sexual function in survivors of testicular cancer. Br J Cancer 2005;93:200-207.

80. Gerl A, Mühlbayer D, Hansmann G, et al. The impact of chemotherapy on Leydig cell function in long term survivors of germ cell tumors. Cancer 2001;91:1297-1303.

81. Xing JS, Bai ZM. Is testicular dysgenesis syndrome a genetic, endocrine, or environmental disease, or an unexplained reproductive disorder? Life Sci 2018;194:120-129.

82. Huyghe $E$, Matsuda T, Daudin M, et al. Fertility after testicular cancer treatments: results of a large multicenter study. Cancer 2004;100:732-737.

83. Spermon JR, Kiemeney LA, Meuleman EJ, et al. Fertility in men with testicular germ cell tumors. Fertil Steril 2003;79(Suppl 3):1543-1549.

84. Brydøy M, Fosså SD, Klepp O, et al. Paternity and testicular function among testicular cancer survivors treated with two to four cycles of cisplatin-based chemotherapy. Eur Urol 2010;58:134-140.

85. Fosså SD, Abyholm T, Aakvaag A. Spermatogenesis and hormonal status after orchiectomy for cancer and before supplementary treatment. Eur Urol 1984;10:173-177

86. Moody JA, Ahmed K, Yap T, et al. Fertility management in testicular cancer: the need to establish a standardized and evidence-based patient-centric pathway. BJU Int 2019;123:160-172.

87. Ostrowski KA, Walsh TJ. Infertility with testicular cancer. Urol Clin North Am 2015;42:409-420.

88. Brydøy M, Fosså SD, Klepp O, et al. Sperm counts and endocrinological markers of spermatogenesis in long-term survivors of testicular cancer. $\mathrm{Br}$ J Cancer 2012;107:1833-1839.

89. Gandini L, Sgrò P, Lombardo F, et al. Effect of chemo- or radiotherapy on sperm parameters of testicular cancer patients. Hum Reprod 2006;21: 2882-2889.

90. Beck $\mathrm{SD}$, Bey $A \mathrm{~L}$, Bihrle $\mathrm{R}$, et al. Ejaculatory status and fertility rates after primary retroperitoneal lymph node dissection. J Urol 2010;184:2078-2080.

91. Subramanian VS, Nguyen CT, Stephenson AJ, et al. Complications of open primary and post-chemotherapy retroperitoneal lymph node dissection for testicular cancer. Urol Oncol 2010;28:504-509.

92. Pettus JA, Carver BS, Masterson T, et al. Preservation of ejaculation in patients undergoing nerve-sparing postchemotherapy retroperitoneal lymph node dissection for metastatic testicular cancer. Urology 2009;73. 328-331, discussion 331-332.

93. Dahl AA, Haaland CF, Mykletun A, et al. Study of anxiety disorder and depression in long-term survivors of testicular cancer. J Clin Oncol 2005; 23:2389-2395.

94. Vehling S, Mehnert A, Hartmann M, et al. Anxiety and depression in long-term testicular germ cell tumor survivors. Gen Hosp Psychiatry 2016;38:21-25.

95. Smith $A B$, Rutherford $C$, Butow $P$, et al. A systematic review of quantitative observational studies investigating psychological distress in testicular cancer survivors. Psychooncology 2018;27:1129-1137.

96. Shinn EH, Basen-Engquist K, Thornton B, et al. Health behaviors and depressive symptoms in testicular cancer survivors. Urology 2007;69:748-753. 
97. Smith $A B$, Butow $P$, Olver I, et al. The prevalence, severity, and correlates of psychological distress and impaired health-related quality of life following treatment for testicular cancer: a survivorship study. J Cancer Surviv 2016;10:223-233.

98. Alacacioglu A, Ulger E, Varol U, et al. Sexual satisfaction, anxiety, depression and quality of life in testicular cancer survivors. Med Oncol 2014;31:43.

99. Amidi A, Hosseini SMH, Leemans A, et al. Changes in brain structural networks and cognitive functions in testicular cancer patients receiving cisplatin-based chemotherapy. J Natl Cancer Inst 2017;109.

100. Amidi A, Agerbæk M, Wu LM, et al. Changes in cognitive functions and cerebral grey matter and their associations with inflammatory markers, endocrine markers, and APOE genotypes in testicular cancer patients undergoing treatment. Brain Imaging Behav 2017;11:769-783.

101. Amidi A, Wu LM, Agerbæk M, et al. Cognitive impairment and potential biological and psychological correlates of neuropsychological performance in recently orchiectomized testicular cancer patients. Psychooncology 2015;24:1174-1180.

102. Wefel JS, Vidrine DJ, Veramonti TL, et al. Cognitive impairment in men with testicular cancer prior to adjuvant therapy. Cancer 2011;117:190-196.

103. Skoogh J, Steineck G, Stierner U, et al. Testicular-cancer survivors experience compromised language following chemotherapy: findings in a Swedish population-based study 3-26 years after treatment. Acta Oncol 2012;51:185-197.

104. Wefel JS, Vidrine DJ, Marani SK, et al. A prospective study of cognitive function in men with non-seminomatous germ cell tumors. Psychooncology 2014;23:626-633.

105. Chovanec M, Vasilkova L, Setteyova L, et al. Long-term cognitive functioning in testicular germ-cell tumor survivors. Oncologist 2018;23: 617-623

106. Bower JE. Cancer-related fatigue-mechanisms, risk factors, and treatments. Nat Rev Clin Oncol 2014;11:597-609.
107. Orre IJ, Fosså SD, Murison R, et al. Chronic cancer-related fatigue in longterm survivors of testicular cancer. J Psychosom Res 2008;64:363-371.

108. Sprauten M, Haugnes HS, Brydøy M, et al. Chronic fatigue in 812 testicular cancer survivors during long-term follow-up: increasing prevalence and risk factors. Ann Oncol 2015;26:2133-2140.

109. Adams SC, DeLorey DS, Davenport MH, et al. Effects of high-intensity interval training on fatigue and quality of life in testicular cancer survivors. Br J Cancer 2018;118:1313-1321.

110. Mustian KM, Alfano CM, Heckler C, et al. Comparison of pharmaceutical, psychological, and exercise treatments for cancer-related fatigue: a meta-analysis. JAMA Oncol 2017;3:961-968.

111. Ventry IM, Weinstein BE. The hearing handicap inventory for the elderly: a new tool. Ear Hear 1982;3:128-134.

112. Abstracts of the 7th Annual Congress of the European Association for Haemophilia and Allied Disorders, February 26-28, 2014; Brussels, Belgium. Haemophilia 2014;20(Suppl 2):1-91.

113. Oldenburg J, Fosså SD, Dahl AA. Scale for chemotherapy-induced long term neurotoxicity (SCIN): psychometrics, validation, and findings in a large sample of testicular cancer survivors. Qual Life Res 2006;15:791-800.

114. Gandaglia G, Becker A, Trinh QD, et al. Long-term survival in patients with germ cell testicular cancer: a population-based competing-risks regression analysis. Eur J Surg Oncol 2014;40:103-112.

115. Miller KD, Siegel RL, Lin CC, et al. Cancer treatment and survivorship statistics, 2016. CA Cancer J Clin 2016;66:271-289.

116. Travis LB, Beard C, Allan JM, et al. Testicular cancer survivorship: research strategies and recommendations. J Natl Cancer Inst 2010;102:1114-1130.

117. Ness KK, Kirkland JL, Gramatges MM, et al. Premature physiologic aging as a paradigm for understanding increased risk of adverse health across the lifespan of survivors of childhood cancer. J Clin Oncol 2018;36: 2206-2215.

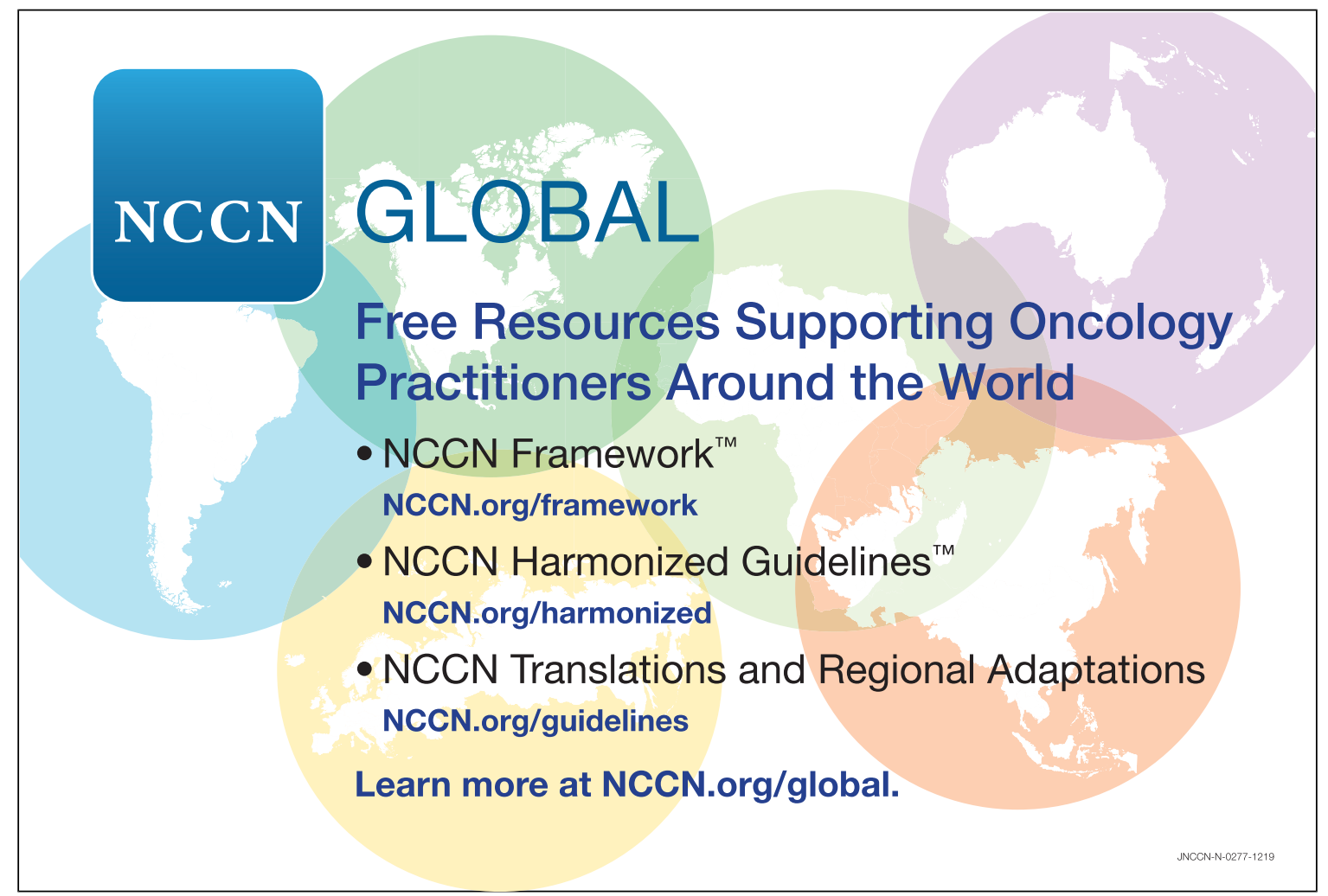


Supplemental online content for:

\section{Testicular Cancer Survivorship}

Chunkit Fung, MD, MS; Paul C. Dinh Jr, MPH; Sophie D. Fossa, MD, PhD; and Lois B. Travis, MD, ScD

J Natl Compr Canc Netw 2019;17(12):1557-1568

eFigure 1: Severity of American Speech-Language-Hearing Association-Defined Hearing Loss According to Cumulative Cisplatin Dose Group

eTable 1: Recommended Management Options for Treatment-Related Complications 


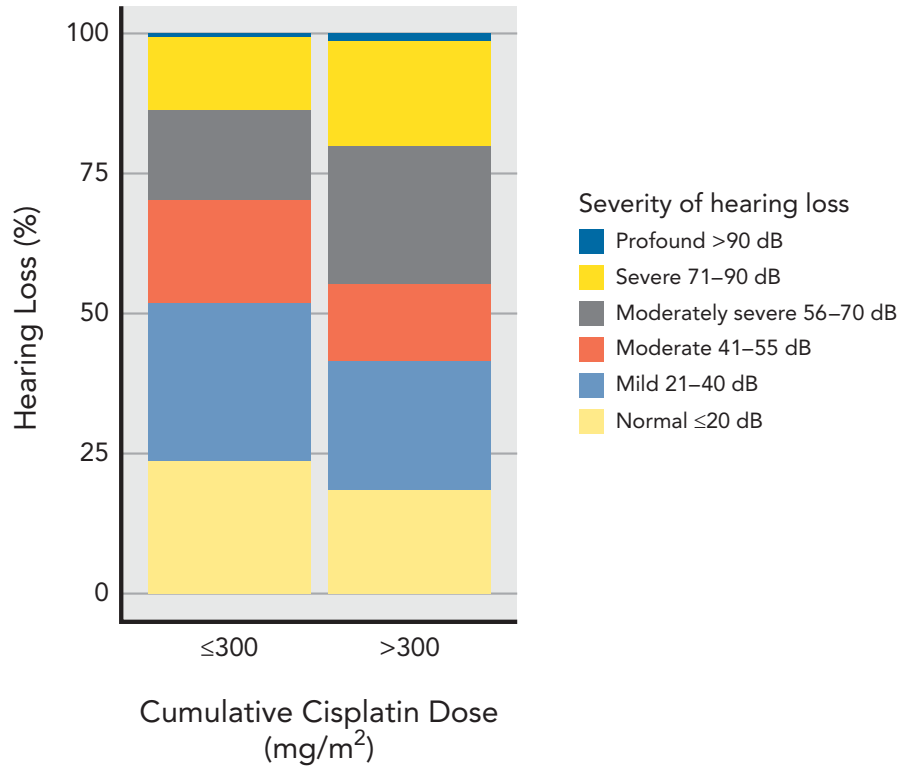

eFigure 1. Severity of American Speech-Language-Hearing Association-defined hearing loss according to cumulative cisplatin dose group. From Frisina RD, Wheeler HE, Fossa SD, et al. Comprehensive audiometric analysis of hearing impairment and tinnitus after cisplatin-based chemotherapy in survivors of adult-onset cancer. J Clin Oncol 2016;34:2717, with permission.

\section{eTable 1. Recommended Management Options for Treatment-Related Complications}

\begin{tabular}{|c|c|}
\hline Treatment-Related Complications & Recommended Management \\
\hline Second malignant neoplasms & $\begin{array}{l}\text { - Healthcare providers should advise TCS to adhere to national cancer screening guidelines applicable to the general } \\
\text { population }{ }^{6} \\
\text { - Every effort should be made to reduce the amount of cytotoxic exposure needed to successfully treat the cancer }\end{array}$ \\
\hline CVD & $\begin{array}{l}\text { - No established evidence-based CVD screening recommendations exist specifically for TCS } \\
\text { - Healthcare providers should counsel TCS about CVD risk-factor modification, advising adherence to guidelines }{ }^{7} \text { for } \\
\text { the general population }\end{array}$ \\
\hline Raynaud phenomenon & $\begin{array}{l}\text { - Raynaud phenomenon-associated symptoms can be prevented by avoidance of cold and other aggravating factors, } \\
\text { including smoking, sympathomimetic drugs, and selected treatments for either attention-deficit/hyperactivity } \\
\text { disorder or migraine headaches }{ }^{8}\end{array}$ \\
\hline Ototoxicity & $\begin{array}{l}\text { - Although there are no effective pharmacotherapies to prevent or treat cisplatin-related ototoxicity, TCS should } \\
\text { minimize noise exposure and avoid other ototoxic agents. }\end{array}$ \\
\hline Neurotoxicity & $\begin{array}{l}\text { - ASCO clinical practice guidelines for } \mathrm{CIPN}^{9} \text { recommend duloxetine for management of pain, because there are no } \\
\text { effective agents available to prevent or treat CIPN }\end{array}$ \\
\hline Nephrotoxicity & $\begin{array}{l}\text { - During cisplatin-based chemotherapy, healthcare providers should avoid nephrotoxic drugs }{ }^{10} \text { and administer intense } \\
\text { hydration }{ }^{11} \text { to minimize the degree of renal damage }\end{array}$ \\
\hline Pulmonary toxicity & $\begin{array}{l}\text { - Before initiation of any bleomycin-containing chemotherapy regimen, healthcare providers should perform a } \\
\text { detailed patient history, including consideration of age, smoking status, and preexisting lung disease, and consider } \\
\text { baseline pulmonary function } \\
\text { - Healthcare providers should also withhold bleomycin at the earliest clinical signs or symptoms of bleomycin-induced } \\
\text { pulmonary toxicities during chemotherapy }\end{array}$ \\
\hline Hypogonadism & $\begin{array}{l}\text { - Healthcare providers should routinely evaluate TCS for hypogonadism symptoms and assess hormonal status } \\
\text { accordingly } \\
\text { - Decisions to administer testosterone replacement therapy should be based on clinical symptoms of hypogonadism, } \\
\text { and referrals to endocrinologists should be considered for challenging } \text { cases }^{10}\end{array}$ \\
\hline Infertility & $\begin{array}{l}\text { - The ASCO clinical practice guideline for fertility preservation }{ }^{12} \text { recommends referral of patients with cancer to } \\
\text { appropriate reproductive specialists if clinically indicated; sperm cryopreservation remains a standard fertility } \\
\text { preservation practice before treatment initiation for interested patients with TC }\end{array}$ \\
\hline Cognitive impairment & $\begin{array}{l}\text { - Because subjective cognitive complaints may reflect the effects of underlying anxiety and depression that are } \\
\text { prevalent in TCS, }{ }^{13} \text { implementation of effective coping strategies should be considered }\end{array}$ \\
\hline Chronic CRT & - Exercise and psychologic interventions should be considered \\
\hline
\end{tabular}

Abbreviations: CIPN, chemotherapy-induced peripheral neuropathy; CRT, cancer-related fatigue; CVD, cardiovascular disease; TC, testicular cancer; TCS, testicular cancer survivors. 